\title{
O uso do RPG no ensino de História: um relato de experiência sobre o Maranhão republicano explicado por meio de um jogo
}

\author{
The Use of RPG in the Teaching of History: An Experience \\ Report on the Republican Maranhão Explained through a Game
}

Eva Dayna Felix Carneiro*

RESUMO

Este artigo descreve uma experiência de elaboração do manual de um jogo voltado para o ensino de História na educação básica. A análise das potencialidades dos jogos de Role Playing Game (RPG) como ferramenta no processo de ensino e aprendizagem nos conduzem a um reconhecimento desta como eficaz mediadora na socialização de conteúdos e na construção de habilidades necessárias à formação de cidadãos seguros, leitores e ativos. Levando isto em consideração, foi criado um manual de RPG pautado na história do Maranhão republicano, objetivado também no intuito de ser uma ferramenta para a valorização da história regional e local, permitindo que alunos e professores tenham uma maior aproximação com a complexidade social local. Neste relato, pretende-se destacar os caminhos da pesquisa e as etapas de construção.

Palavras-chave: ensino de História; RPG; Maranhão.

\section{ABSTRACT}

This article describes an experience in preparing a game manual aimed at teaching History for the basic education. Analysing the potential of Role Playing Games (RPG) as a tool in the teaching and learning process, leads us to recognize it as an effective mediator in the socialization of content and in construction of skills necessary for developing assertive, reading driven and active citizens. Taking that into account, an RPG manual centered in the history of Maranhão was created, also aiming to be a tool for the valorization of regional and local history, allowing students and teaches to have a higher assessment with the local social complexity. This report intends to highlight the research paths and the construction stages of the game manual.

Keywords: History teaching; RPG; Maranhão.

\footnotetext{
* Instituto Federal do Maranhão (IFMA), Santa Inês, MA, Brasil. eva.carneiro@ifma.edu.br
} 
O ensino na educação básica é marcado por uma série de particularidades impostas pelos novos tempos, de popularização dos meios de comunicação, de um universo atrativo e desafiador presente nas telas de tablets, celulares e computadores. Em meio a esses tempos de novas tecnologias, de um mundo conectado, com apelos a velocidade e interatividade, um dos maiores problemas pedagógicos enfrentados pelos profissionais da educação é a construção de estratégias que consigam dialogar com esse universo e estimulem os alunos a se interessarem mais pelos conteúdos trabalhados em sala de aula. Seguindo essa trilha, não são novas as reflexões que se propõem a pensar diferentes métodos de aprendizagem focados na autonomia de participação dos alunos, e que priorizam uma educação que tem por base a participação mais ativa no processo de aprendizagem. São metodologias para as quais, o professor deve atuar como um mediador/facilitador e o aluno o agente no centro do processo.

A escola deve atuar como influenciadora na formação de cidadãos dotados de uma visão crítica de mundo, com respeito às diferenças e espírito participativo e colaborativo. Apesar dos avanços na forma como se pensa a educação escolar, com a inclusão de novas metodologias e tipos de abordagens, nesse ambiente ainda existem resquícios de uma educação tradicional/conservadora, com reduzido apelo à diversão e ao diálogo. Por isso, a adoção de jogos dentro das salas de aula se torna uma alternativa tão importante. Como reforço a este pensamento, Priscila Jann e Maria Leite justificam que os jogos didáticos entram no cenário atual, "pois são práticos, fáceis de manipulação nas salas de aulas, têm um custo reduzido e promovem o processo de aprendizagem de uma maneira estimulante, desenvolvendo as relações sociais, a curiosidade e o desejo em adquirir mais conhecimento" (2010, p. 283). Além de promover o conhecimento, as autoras acreditam que ele estimula a cooperação e companheirismo; importantes habilidades para a superação de inseguranças, problema presente no cotidiano de boa parte dos alunos, que vivem o delicado momento da adolescência. Deste modo, das tentativas de conjugação de outros elementos para a sala de aula, de montar estratégias de aproximação dos alunos aos conteúdos ministrados, atentamos para a relevância do uso do Role Playing Game (RPG) no ensino de História.

Role Playing Game pode ser traduzido como um jogo de interpretação de papéis. Nele, os jogadores atuam na construção de personagens, definindo atributos a exemplo de quanto o personagem tem de força, carisma, destreza 
e, ainda, traços da personalidade. São essas características, definidas pelo jogador, que irão nortear as atitudes do personagem no jogo. Dentro de sua dinâmica, existem os jogadores que irão interpretar papéis e o mestre, que é o responsável pela condução da história. É o mestre quem expõe uma determinada situação fazendo uma descrição do cenário e dos personagens auxiliares, permitindo que os jogadores “imaginem” o que está acontecendo e sejam instigados a pensar na resolução dos problemas que vão aparecendo no decorrer da narrativa. O desenvolvimento dos personagens não é definido pelo mestre, mas pelos próprios jogadores que decidem as ações que seus personagens devem tomar. O desenrolar do jogo se dá de acordo com um sistema de regras predeterminado a guiar os jogadores, que por seu turno, devem improvisar livremente, de modo que as escolhas feitas pelos participantes determinam a direção tomada pela narrativa. Deste modo compreende-se o RPG como um jogo de construção coletiva.

No Brasil, o jogo de interpretação de personagens começou a se popularizar na década de 1990, quando surgiram os primeiros impressos sobre RPG no país. Foi neste período que Thomas Massao Fairchild constatou um aumento dos discursos sobre o uso do RPG para o ensino no país para dar um "aproveitamento didático no exercício da diversão” (2007, p. 319). Não à toa, o manual $O$ desafio dos bandeirantes, de 1992, que foi uma das primeiras produções dessa linha feita no país, apoia-se na história do bandeirantismo para a sua construção.

Ainda nos anos de 1990, Alfeu Marcatto lançou o livro Saindo do quadro, de 1996. Nele, o autor faz uma breve descrição do que é RPG e destaca os principais títulos disponíveis no Brasil na época de sua publicação. Marcatto sugere que uma metodologia utilizando o jogo apresenta como um dos principais pontos positivos a fuga da "monotonia dos manuais pedagógicos" e, além disso, essa forma de abordagem oferece subsídios para que professores, independente do grau e da disciplina em que atuam, permitam que suas aulas fiquem mais produtivas, animadas e interativas. Deste modo, o autor coloca como proposta aos professores a apropriação do jogo no intuito de tornar as aulas mais atrativas, cativantes e que despertem interesse nos docentes, o que poderia facilitar o envolvimento do aluno com o tema que se propõe a discutir (MARCATTO, 1996).

Outra obra de fôlego sobre o tema ainda nos anos 1990, foi a tese de dou- 
torado de Sônia Rodrigues Brasil, de 1997, intitulada Roleplaying Game e a pedagogia da Imaginação no Brasil. Em sua pesquisa, a autora faz uma relação entre o jogo e a literatura, apontando como mestres de RPG se apropriam de personagens e tramas literárias, destacando ainda a importância da produção de textos por parte dos alunos. Segundo a autora, as aulas com sessões de RPG, estimulam a criatividade e, como consequência disso, melhora a produção de textos narrativos. Seguindo este caminho, Wagner Schmit destaca também a importância dos eventos sobre RPG e educação para o encaminhamento dessas discussões, sendo o primeiro deles o Simpósio de RPG e educação em São Paulo no ano de 2002. Este evento possibilitou uma maior visibilidade das práticas de uso do RPG e das trocas de experiências entre profissionais que a utilizavam como ferramenta de auxílio pedagógico. Ideias, como a do aluno construindo o seu próprio conhecimento, têm sido consideradas em proposições curriculares e ações pedagógicas que veem no jogo a possibilidade de ampliação dessa participação.

Neste universo de discussão, em que nos interessa primordialmente a relação entre o RPG e o ensino da História, observa-se que este trava constantes lutas contra modelos ultrapassados, que privilegiam um olhar eurocêntrico para o estudo do homem no tempo e espaço e, ainda, contra resquícios de um sistema de ensino que privilegia a memorização de fatos e datas. Jeanne Silva (2002) e Eli Cardoso (2008), trouxeram importantes colaborações para as reflexões em torno do Role Playing Game como ferramenta de ensino da História. As duas pesquisadoras o entendem como uma ferramenta útil para as aulas. Jeanne Silva destaca que

se o RPG tem sucesso entre os adolescentes, acreditamos que, como profissionais da História, não podemos desprezar esse tipo de recurso, sabendo extrair dele as vantagens que nos pode oferecer como instrumento que desperte a atenção e a motivação para o ensino da História. (SILVA, 2002, p. 57)

De acordo com essa pesquisadora, uma das vantagens do uso do RPG seria o incentivo à formação e pesquisa histórica para a criação dos personagens, do cenário e da trama. Reconhecimento compartilhado por Eli Cardoso (2008), quando aponta essa como uma "estratégia diferenciada" de ensino, que sinaliza novos caminhos para o processo de ensino-aprendizagem de História. Discutindo em torno de um relato de experiência, a autora conclui que a prin- 
cipal contribuição do jogo foi o seu caráter motivador, estimulando os alunos para o aprendizado. Mesmo as duas pesquisas seguindo por caminhos distintos, a primeira mais preocupada com a pesquisa histórica, teoria e método, e a segunda trilhando pelos rumos da psicologia da educação, ambas apontam para o mesmo resultado, a positividade do uso desta ferramenta.

$\mathrm{Na}$ atualidade, existe um reconhecimento do Role Playing Game como importante ferramenta pedagógica, eficaz mediadora na socialização de conteúdos e na construção de habilidades necessárias à formação de cidadãos seguros, leitores e ativos, especialmente, por permitir que os jogadores construam os personagens a serem interpretados. Assim, o RPG se torna uma importante ferramenta por aliar imaginação, interpretação, socialização e aventura, pois, nas diferentes etapas que configuram uma aventura de RPG, os alunos são estimulados a estudar ao mesmo tempo em que desenvolvem habilidades cognitivas e sociais. De acordo com Marcatto (1996), um dos pontos positivos da utilização do RPG na educação consiste no fato de que nas aventuras não existe um vencedor, posto que, este não é um jogo competitivo. Acrescido a isso, ele incentiva a leitura, a escrita e a pesquisa, ao passo que, para a construção dos personagens, faz necessário um prévio estudo da ambientação do jogo, bem como a construção de uma história prévia para os personagens, o que, por seu turno, reforçaria a necessidade de consulta aos manuais e à pesquisa em outros meios.

É importante frisar ainda que, ao mesmo tempo em que os alunos, em contato com esse tipo de jogo, têm a possibilidade de produzir as narrativas, essas também expressarão a sua própria percepção da experiência humana no tempo, exercício primeiro do estudo da História. Pois, como nos alerta Juliano da Silva Pereira (2014), não podemos negar a historicidade da construção narrativa do aluno. Deste modo, o RPG pode trazer à escola, mais do que a interatividade, uma efetiva participação dos discentes no ensino, posto que os estudantes assumem dentro desta perspectiva o papel de construtores do conhecimento em parceria com os professores.

O Ministério da Educação vem, inclusive, reconhecendo a importância do RPG nas salas de aula e incitando os profissionais da área a adotarem essa ferramenta. Através do portal do professor, mantido pelo MEC, podemos encontrar diferentes aulas com RPG, assim como no Cadernos de Práticas, na página da Base Nacional Comum Curricular, em que também podemos encon- 
trar experiências com essa modalidade de jogo aplicadas ao ensino. Vale acrescentar que a prática do RPG enquanto escolha pedagógica no ensino da História é capaz de possibilitar ao aluno a pesquisa e a reflexão sobre o mundo que o cerca. Um jogo que tenha como cenário a localidade a qual pertence, com personagens e nomes que lhes são familiares de alguma maneira, colabora para a construção de um olhar mais atento para o universo ao qual se encontra imerso. Neste sentido, já existem no mercado vários manuais voltados para o uso escolar do RPG, com forte apelo ao uso da História, como é o caso, entre outros, de Entradas e Bandeiras, Quilombo dos Palmares, O descobrimento do Brasil, todos de Luiz Eduardo Ricon.

Pensando nas potencialidades dos jogos no processo de ensino e aprendizagem, foi desenvolvido no IFMA, campus Santa Inês, com apoio financeiro da instituição, o projeto de pesquisa "RPG e História: o lúdico no processo educativo de valorização da História regional”, que se propôs a elaborar um jogo de Role Playing Game, ambientado na História do Maranhão republicano. O referido projeto também foi justificado por sua importância na socialização dos saberes produzidos pelo IFMA para a comunidade que o cerca e por uma maior aproximação dos discentes com a História do Maranhão contemporâneo. Ponto em que reforça o pensamento de Circe Bittencourt (2012) quando critica o trato atual da História nacional, que vem sendo deixada para segundo plano, dando lugar a uma História geral ou global. O sistema econômico, atrelado ao estágio de uma mundialização da economia, relega a abordagem do nacional a algo menos importante, embora haja muitas correntes historiográficas que rompam com o modelo de ensino vinculado a padrões político-econômicos. O mesmo tipo de crítica é feito à História regional subordinada à História nacional.

De acordo com Márcio Henrique Gomes (2015, p. 23), o local “se encontra, de certa forma, desvinculado do saber histórico escolar, sem o devido valor entre docentes e discentes, o que contribui para o pouco conhecimento da História e cultura local”. Neste sentido, a compreensão das relações entre local/ regional e geral configura-se como elemento edificante de um olhar crítico sobre os processos históricos, e conduz a importantes reflexões sobre noções como a de identidade e desenvolvimento regional. No cenário atual, a História regional, tem permanecido, por vezes, longe dos interesses e alcance dos alunos. Colabora para esse fenômeno, que também está relacionado à adesão das 
universidades públicas ao Exame Nacional de Ensino Médio (ENEM), uma significativa carência de material didático que tenha como foco a História local. Assim, a experiência de criação de um jogo ambientado no Maranhão republicano esteve fundada na necessidade de uma maior aproximação dos alunos com a História local/regional, despertando o interesse para diversidade histórica, por meio do contato com uma alternativa aos modelos mais generalizantes de ensino.

Nessa relação entre o RPG e a aprendizagem histórica, nos recorremos também à noção de empatia histórica destacada por Juliano Pereira. Para o autor, "empatia tem uma relação com a imitação, uma simulação que faria com que pudéssemos nos sentir como o objeto com o qual estabelecemos uma relação empática" (2014, p. 34). Desse modo, para que o aluno consiga chegar a uma maior compreensão histórica é necessário que ele desenvolva uma "performance empática”, que está relacionada ao processo de identificação daquilo que se está estudando - ou seja, do conhecimento "escolar" - com a história do discente. Neste processo, leva-se em consideração as vivências e conhecimentos dos próprios alunos, pois estes seriam a base fundamental para que o estudante consiga ter empatia por aqueles sujeitos que está estudando. Então, o RPG pode ajudar como importante ferramenta, pois o jogo estimula nos participantes esse exercício empático, já que o jogador representa um personagem, tendo de se colocar no lugar deste, e, a partir daí, sendo colocado a refletir sobre suas ações e como aquele sujeito reagiria a determinadas situações, em um exercício fecundo de empatia histórica.

Clarice Ferreira também reforça a noção de empatia histórica destacando que

empatizar historicamente é compreender os motivos e explicar as ações dos homens no passado, de modo a torná-las inteligíveis às mentes contemporâneas. Tal implica um amplo conhecimento do respectivo contexto histórico e a interpretação da evidência histórica diversificada e/ou contempladora de diferentes perspectivas, estando também vinculado o uso da imaginação histórica. (FERREIRA, 2009, p. 116-117).

Dentro dessa conceitualização de empatia histórica, mais do que se colocar no lugar do outro, a autora nos alerta para a potencialidade desse exercício ao fazer com que os alunos compreendam o porquê de determinados agentes do 
passado possuírem práticas e ações específicas, diferentes das que eles teriam no presente. Pela empatia, determinadas ações tomadas no passado podem deixar de ser observadas com estranheza e deslocamentos, pois, mesmo sem concordar, os alunos podem entendê-las de forma localizada historicamente, como fruto de um contexto, assim, inteligíveis às mentes contemporâneas.

Somado a isso, a narrativa também está presente tanto no conhecimento histórico quanto no jogo. Através do uso do RPG em sala, os professores têm a possibilidade de fazer os alunos vivenciarem uma espécie de imersão imaginativa em um determinado momento, como o Maranhão republicano, ambientação do manual que aqui destacamos. Por meio do jogo, e o fato de uma partida de RPG se assemelhar em muito a uma peça de teatro, o aluno é levado a construir mentalmente uma narrativa do passado que lhe é mais próxima e viva do que aquelas encontradas nos manuais, facilitando o reconhecimento tanto do personagem como de si mesmo como agentes históricos, capazes de tomar decisões e influenciar nos rumos da sociedade em que se está inserido.

A noção de imaginação histórica também é um conceito chave para se pensar a relação entre RPG e conhecimento histórico. Hayden White, com o seu livro Meta-história: a imaginação histórica do século XIX, provocou uma série de debates acerca da produção do conhecimento histórico, especialmente as noções de "verdade" e "ficção" na escrita da História. É manifesto que toda produção de conhecimento envolve exercício imaginativo, posto que sempre é permeada de representações, levando à desconstrução da ideia de uma escrita da verdade absoluta sobre o passado, nos dizeres de Meri Machado, o que torna limitante qualquer "possibilidade de escrita ou ensino da História sem o reconhecimento dos elementos metafísicos ou ficcionais contidos nas diferentes formas narrativas" (2018, p. 23). No RPG, além do apelo a uma espécie de narrativa, é justamente a imaginação que dá sentido à brincadeira. Depreende-se daí que o RPG pode, de acordo com Juliano Pereira, “inferir sobre o passado, construindo (através de uma imaginação histórica), assim, um pensamento histórico mais requintado; compreender o outro em sua diferença" (2014, p. 58).

A ponderação dessas questões levou à construção do livro História e imaginação no Maranhão republicano. Este manual apoia-se em elementos da fantasia, embasados na mitologia fantástica do estado e também em dados históricos sobre a região que se iniciam com a adesão do estado à república. 
Assim, ele não deixa de ser um jogo de fantasia, mas que se pretende colaborar com o estudo da História regional. Assim como qualquer outro jogo de RPG, apoia-se na ideia de que não deve haver um vencedor, pois mais importante do que vencer, é se divertir com a história que está sendo contada.

\section{DA CONSTRUÇÃO DO MANUAL}

A criação do manual com elementos da história da região mostrou-se uma estratégia eficiente para amenizar a carência da gamificação no espaço escolar, pois compreende-se que o lúdico se torna uma proposta educacional para o enfrentamento das dificuldades no processo ensino-aprendizagem. Também, revelou-se como aliado às reflexões sobre a necessidade de aproximação dos alunos ao contexto que os cerca, de uma melhor compreensão sobre a sua própria história, identidade, cultura, entre outros. Assim, o presente relato de experiência sobre a criação do manual compartilha saberes para a prática docente no ensino da História. Divulgar como um instrumento simples, com pouco custo, como um manual de RPG, pode ser também pensado por outros profissionais da área. Esse é um campo rico e cheio de possibilidades, que permite aos historiadores criarem um canal divertido de discussão sobre a História local.

A ideia de construção de um manual de RPG surgiu a partir da experiência de um projeto de extensão intitulado ACERTO CRÍTICO: uso do jogo de RPG como ferramenta interdisciplinar de ensino no IFMA - Campus Santa Inês. Aquele tinha por objetivo primeiro possibilitar a compreensão e aplicação do Role Playing Game como ferramenta didática oportuna à construção e desenvolvimento de conhecimentos a partir da promoção de atividades de extensão (palestras e oficinas) para servidores e alunos da instituição, bem como a comunidade em geral. Para tanto, impôs-se como meta a implementação de um clube de RPG de mesa como uma opção de atividade interdisciplinar de ensino. O que, por seu turno, facilitaria a mobilização da comunidade escolar para estratégias prazerosas e estimulantes no ambiente escolar, como o uso de jogos, além de possibilitar a interação entre alunos e professores de disciplinas distintas. Era interesse, ainda, proporcionar troca de saberes entre o corpo docente, discente e comunidade em geral a partir do estímulo do uso da imaginação e criatividade pela prática do RPG de mesa no ambiente escolar. 
Na execução do projeto, contamos com dois momentos distintos, porém complementares, relacionados à temática do RPG de tabuleiro como estratégia didática. O primeiro a partir da realização da palestra Conceitos gerais sobre o jogo de RPG e a sua aplicação como ferramenta pedagógica com dois convidados, especialistas da área. O segundo momento consistiu na realização de oficinas para tirar dúvidas e observar de maneira prática como jogar, além claro, montar mesas de diferentes jogos. Esse momento associou teoria e prática, através das mesas de Hora de aventura, Medieval/Elfos, Zumbi, Medieval, Heróis, Cyberpunk, Tormenta. Todas as atividades foram abertas a servidores, discentes e comunidade local. Por fim, dessas atividades de extensão formou-se um grupo de alunos, com muita imaginação, interessados em mais atividades do gênero, que se dispuseram a participar do projeto de criação de um manual próprio.

A partir daí começamos os primeiros passos para a elaboração do manual. Já se tinha clareza de que este precisava ser ambientado no Maranhão, e teria como um dos principais elementos de sua composição a própria história do estado. Assim, para que o projeto pudesse ter o melhor andamento, um embasamento literário/científico foi feito em sua parte inicial, na qual focamos na pesquisa sobre outros trabalhos de RPG que tratassem da história do Brasil. Ter acesso a essas produções foi importante para compreendermos o estilo e as formas como as mecânicas eram introduzidas nestes cenários, como outros autores se apropriavam de elementos históricos para a composição de seus games.

De início conseguimos encontrar alguns livros, como por exemplo: Aúreos: Dançarinos da Lua - um RPG com vários elementos de culturas afrodescendentes como orixás, tendo como cenário um Brasil colonial fantástico; Brasil Colonial: Aventuras Capixabas, que retrata a história do Estado do Espirito Santo; Mini GURPS: Terra de Jagunços - cujo cenário é o sertão nordestino e toda a mística e superstições particulares desse lugar; por fim, Mini GURPS: Entradas e Bandeiras - RPG sobre os bandeirantes paulistas. Todas as leituras foram seguidas de um fichamento. Esse processo foi de vital importância visto que os encaminhamentos teóricos e metodológicos que seguimos na construção do nosso manual teve a experiência desses outros trabalhos como referência.

Em momento posterior ao fichamento dos manuais, foi dada especial atenção à bibliografia acerca da história do Maranhão. Este acervo foi com- 
posto por uma diversidade de fontes como livros, artigos e dissertações. Esta pesquisa bibliográfica foi importante para a nossa delimitação, haja vista que, chegamos à conclusão de que para o guia precisaríamos de um recorte temporal. Após analisar esse material e elencar eventos importantes no estado, optamos por dar enfoque a história do Maranhão Republicano. A partir daí, elencamos alguns acontecimentos marcantes desse período, e estes foram selecionados para comporem o corpo do manual, dentre eles cabe citar: tenentismo no Maranhão - em especial Reis Perdigão -, oligarquias maranhenses no período de 1945 a 1965 e o Maranhão na ditadura civil-militar.

Cabe destacar que este recorte não atuou como uma camisa de força. Alguns elementos que consideramos interessantes na história local e que ocorreram em diferentes períodos também poderiam entrar para compor esse Maranhão fantástico que gostaríamos de criar. Como foi o caso da emblemática história da senhora de escravos que viveu no século XIX, Ana Jansen ${ }^{1}$, fora do nosso recorte, mas que por fazer parte do imaginário popular da região, optamos por incluir como uma personagem não jogável, ou inglês, como é popularmente conhecido, non-player character - NPC.

O grupo, que era formado apenas por alunos do ensino médio, se uniu para testar diferentes sistemas de RPG em algumas aventuras, para que assim pudéssemos optar pelo que mais se encaixasse na nossa proposta: fazer um jogo simples, com mecânica fácil, que pudesse ser utilizado tanto por alunos quanto professores da educação básica. E assim, após os testes, verificamos que o sistema de clãs ficaria mais simples do que o de classe e raça, focado ao estilo do sistema Storyteller, ou seja, com mais ênfase na criação das histórias e na interpretação.

O Maranhão possui uma grande diversidade de povos e culturas, cada grupo possui uma série de hábitos e costumes que estão ligados à sua própria história. No manual, não pretendemos findar ou apresentar toda a mistura cultural que compõe o estado. Ao contrário, temos ciência de que este é um estudo limitado e que muito ficou de fora. Apesar disso, pretendeu-se provocar a discussão sobre a existência desses grupos, suas culturas e lutas, que, em alguns casos, é pela própria sobrevivência. Os grupos escolhidos para centrar nossa narrativa foram: Quebradeiras de coco babaçu, Quilombolas, Indígenas, Oligarcas e Encantarias.

As Quebradeiras de coco, de maneira geral, são mulheres fortes e muito 
presentes na região central e nordeste do Maranhão, com acentuada presença em torno do município de Caxias e no Médio Mearim, ocupações marcadas por deslocamentos de camponeses dos estados do Nordeste como Piauí, Ceará, Paraíba e Pernambuco. Cabe destacar que, de acordo com Andrade, "além dos nordestinos que chegaram nas frentes agrícolas, já se encontravam em povoados na região ex-escravos, desde a abolição da escravidão ou do declínio das fazendas de engenho de cana, nos séculos XVIII e XIX" (ANDRADE apud FIGUEIREDO, 2005, p. 57). É emblemática a história das quebradeiras de coco no estado pois, ao longo do século XX, elas tiveram de passar por várias lutas pelo reconhecimento e preservação de sua atividade, conflitos iniciados ainda anos 1960 que vão estabelecer o sistema de arrendamento de terras, cujo desdobramento foi a ampliação das fronteiras da pecuária e a consequente derrubada de matas para a plantação de capim. Os anos de 1980, por seu turno, configuram um marco nas lutas das quebradeiras de coco, que passaram por intensos conflitos dada a escassez de terras para o extrativismo e para a agricultura familiar, como resultado da Lei de Terras estadual dos anos 1970, que aumentou a grilagem e, mais uma vez, o espaço da pecuária, deixando um número crescente de famílias da região submissas aos grandes proprietários de terras. Tanto pela importância de sua luta quanto pelo próprio apelo que o babaçu tem para a localidade, entendemos que a história dessas mulheres deveria ser priorizada e incluída. Assim, esse clã é formado por mulheres fortes, determinadas, seguras e firmes, e estão intimamente ligadas a natureza, por conta disso, é uma das principais preocupações do grupo a defesa e conservação do meio ambiente.

Os Quilombolas: apesar de uma boa parte dos quilombolas de hoje estarem historicamente ligados às comunidades formadas por escravos que fugiam e procuravam as chamadas "terras de pretos" em busca de sua liberdade, eles não se resumem a isso. Existiam grupos que recebiam as terras como herança, ou até como doação dos seus antigos senhores, além de casos em que as pessoas se uniam e juntavam dinheiro para comprar suas próprias terras. Existem os chamados quilombos contemporâneos, cuja identificação está mais relacionada à identidade, o território, a memória e a autoidentificação ${ }^{2}$. De acordo com a Fundação Palmares, até 2019, o Maranhão contabilizava 518 certidões e 713 comunidades reconhecidas, pulverizadas por todo o estado, sendo assim, uma parcela considerável da população que merece a sua representatividade. Para 
a criação de uma identidade desse clã, optamos por valorizar os traços ligados à ancestralidade africana. Assim, no jogo, os quilombolas carregam a espiritualidade e traços físicos da população afrodescendente.

Os Indígenas: o estado do Maranhão possui diferentes comunidades indígenas distribuídas em 16 áreas que compõem uma considerável parcela dos habitantes. Atualmente, as comunidades indígenas estão localizadas nos municípios de Bom Jardim, Zé Doca, Monção, Carutapera, Amarante, Montes Altos, Grajaú, Barra do Corda, Pindaré, Bom Jardim e na região do Alto Turiaçu (BOTELHO, 2019, p. 27). Hoje, avalia-se que cerca de 30.000 índios vivem no Maranhão, pertencentes a oito nações diferentes. Segundo Francivaldo Melo (2006, p. 48-50), as 16 reservas indígenas no Maranhão estão divididas entre as etnias Urubu Kaapor, Guajará, Guajá, Timbira, Guajajara, Kanela, Gavião Katigê e Krikati (Timbira). No RPG, o jogador tem a liberdade de optar por ser um Urubu Kaapor, mestres na arte plumária; Timbiras, que trabalham com palha trançada: cestos, esteiras e faixas; ou Guajajara, que laboram artisticamente com cestaria e redes de dormir. Estes são apenas alguns exemplos. As culturas indígenas são bastante diversas e estão em constante movimento, a exemplo de toda cultura que se modifica e se reelabora, sem influenciar na identidade de outras etnias. No manual, eles assumem atributos relacionados à caça e uma relação íntima com a natureza, além da rixa histórica com os oligarcas.

O clã dos Oligarcas, apesar de ser multifacetado, congrega toda classe que detém o poder da região seja político, territorial ou econômico. Tem desavenças com os outros clãs por conta de conflito de interesses. Por meio deste clã contamos um pouco da história do poder na região, de como se articulava a oligarquia no Maranhão da primeira república, através de figuras como Benedito Leite e Urbano Santos; como o estado vivenciou o vitorinismo ${ }^{32}$ nos idos de 1930 e suas íntimas relações com o período do Estado Novo no Brasil; e, por fim, o longo período em que o estado foi governado pela família Sarney, conhecido como Sarneísmo, que, apesar de pautar-se em um discurso exaltando a ideia de construção de um Maranhão novo, apoiava-se no regime ditatorial de 1964, que lhe abriu caminho para assumir o governo do estado, mantendo as estruturas de poder vigentes. No jogo, os oligarcas compõem um seleto grupo que dispõe de reconhecido poder econômico e delineiam o mandonismo sob determinadas circunstâncias. 
O último clã é o das Encantarias. Eles condensam todo o caráter misterioso e mágico dessa terra, caracterizados pelo uso de magias e o conhecimento de lendas e mitos. A cultura das encantarias é presente no dia a dia maranhense, seja através de práticas ou rituais nos chamados "terreiros de mina", seja pela memória de narrativas que ainda permeiam o imaginário popular. Os encantados "são entidades espirituais, seres humanos ou animais que encerraram seu ciclo mortal e se tornaram imortais" como bem nos define Liana Trindade no prefácio de Maranhão encantado: encantaria maranhense e outras histórias (FERRETTI: 200, p. 2). São entidades cujas forças são provenientes da natureza e vivem nas matas, rios e marés. Trata-se, também, de divindades construídas a partir das práticas sociais. É importante lembrar que embora sejam entidades consideradas pagãs no meio ortodoxo, elas compõem os sistemas de crenças do catolicismo popular e também cobrem elementos católicos ou de outras religiões. É o caso, por exemplo, da Mãe d'água com o batismo das crianças. $\mathrm{O}$ jogador que escolher este clã deverá definir na sua ficha que tipo de encantado ele deve ser. Dessa forma, os poderes e magias devem estar relacionados ao tipo de encantaria que se quer definir, por exemplo, Surrupira, Mãe d'água, Transmorfos etc.

Para que não ganhasse uma tônica maniqueísta e todos os clãs se colocassem de maneira atrativa, decidimos que o jogador optaria por um clã e dentro dele escolher uma tendência, que no universo fantástico do Maranhão republicano, podem ser Cuxá ou a Vinagreira, cujos nomes estão relacionados a um importante item da culinária maranhense: o cuxá4. Vale lembrar que as tendências não aparecem como algo hermeticamente fechado, como já dito, mas como uma inclinação, que pode se manifestar. Assim, por mais que o jogador escolha um clã que esteja ligado ao mandonismo e poder, o que nos levaria a uma interpretação rasa desse como alguém pouco empático, o jogador tem a liberdade de escolher a tendência do seu personagem, possibilitando, por exemplo um oligarca ter a bondade e a empatia como traço de personalidade.

Para a delimitação dos clãs, atribuímos a diferentes alunos a função de pesquisarem mais sobre cada um dos grupos citados. Após a pesquisa, estes deveriam elaborar como seriam representados no jogo, especialmente a aparência da indumentária e as armas utilizadas por eles, que, por seu turno, deveriam estar relacionadas à cultura e aos costumes de cada grupo. Assim 
iniciamos a fase de ilustração do jogo. Neste momento cada clã recebeu um símbolo que o representasse. Para cada um deles, foram pesquisados elementos próprios das vivências do grupo para colaborar nas ilustrações, como pode ser observado nos passos para a ilustração das Quebradeiras de coco ${ }^{5}$ :

Figura 1 - Esboço roupa Quebradeiras de coco

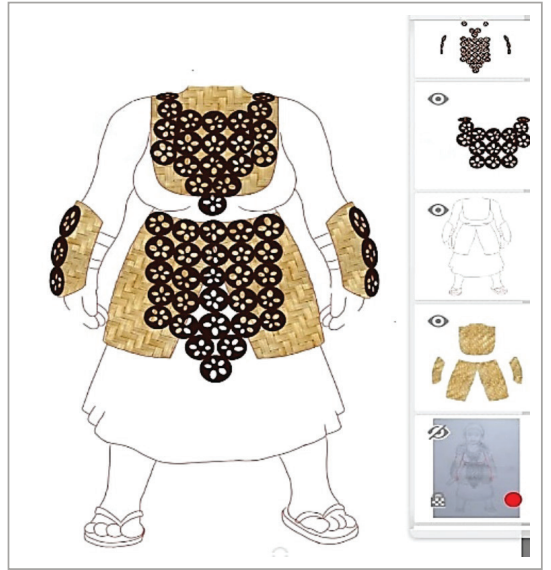

Fonte: História e imaginação no Maranhão republicano, 2019, manuscrito ainda não publicado.

Figura 2 - Versão final Quebradeira de coco

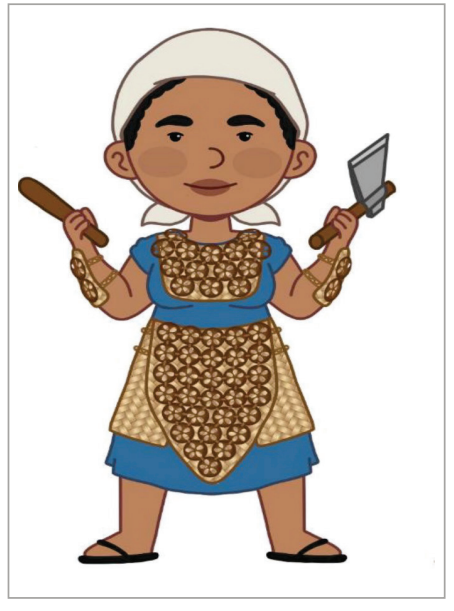

Fonte: História e imaginação no Maranhão republicano, 2019, manuscrito ainda não publicado. 
Como pode ser observado nas ilustrações, foram tomados elementos do coco babaçu que serviram como base para a criação de uma espécie de "cota de malha" composto por medalhas feitas a partir deste material, ao modelo maranhense, ao invés de ferro forjado, com estrutura que é mais dura e resistente, cortado em lâminas, muito utilizado localmente para artesanato. Por baixo dessa "cota", nós temos uma estrutura feita de palha trançada, incorporada aqui pelo fato de esse ser um dos caminhos dados para um aproveitamento total da palmeira, cuja palha tem uma importância econômica e popular muito grande para a região. As palhas trançadas servem para a cobertura de casas mais humildes do interior do estado e, dentre outros, é matéria- prima para a construção de cestas e papel. Elas também usam um lenço na cabeça que as protege do sol e ajuda a equilibrar os cestos de palha. Da mesma forma que com as Quebradeiras de coco, os elementos que compõem a estética dos outros clãs também estão montados a partir de informações sobre suas culturas e hábitos.

Passadas a fase de criação de conceito e características dos clãs, passamos às mecânicas individuais de classes e o funcionamento do combate. Foi criada uma mecânica simples para que até mesmo pessoas que nunca jogaram RPG pudessem entender sem dificuldades. Juntamente, armas e armaduras tiveram valores e tipos atribuídos, inspiradas em elementos característicos de cada clã. Como foi o caso das Quebradeiras de coco presente na Figura 2. Nela pode-se observar o tipo de arma que os membros do clã utilizam, sendo as principais um porrete e um machado. Estes são instrumentos comuns de trabalhos entre homens e mulheres que atuam na extração da castanha de babaçu.

Levando em consideração os hábitos de cada grupo, e para uma melhor organização do tipo de dano que os personagens possuem, dividimos estes em magias e armas. Em relação às armas, construímos uma tabela com a descrição da arma, o dano e as propriedades. Como se vê no demonstrativo abaixo para as armas de longa distância: 


\begin{tabular}{|c|c|c|c|}
\hline \multirow{9}{*}{$\begin{array}{l}\text { Armas a } \\
\text { distância }\end{array}$} & Arco curto & $1 \mathrm{~d} 6$ & $\begin{array}{l}\text { Munição (distância 5/15), duas mãos, } \\
\text { índio +1 de dano }\end{array}$ \\
\hline & Arco longo & $1 \mathrm{~d} 8$ & $\begin{array}{l}\text { Munição (distância 5/30), duas mãos, } \\
\text { índio }+2 \text { de acerto }\end{array}$ \\
\hline & Chicote & $1 \mathrm{~d} 6$ & Alcance, Jagunço +1 de dano \\
\hline & $\begin{array}{l}\text { Babaçu } \\
\text { flamejante }\end{array}$ & $1 \mathrm{~d} 8$ & $\begin{array}{l}\text { Arremesso }(2 / 10) \text {, quebradeira }+2 \\
\text { de acerto }\end{array}$ \\
\hline & Escopeta & $1 \mathrm{~d} 10$ & $\begin{array}{l}\text { Munição }(3 / 10) \text {, queima roupa, } \\
\text { Aristocrata }+1 \text { de acerto }\end{array}$ \\
\hline & Estilingue & $1 \mathrm{~d} 4$ & Munição (4/10), duas mãos \\
\hline & Funda & $1 \mathrm{~d} 6$ & Munição (4/10), índio +1 de acerto \\
\hline & $\begin{array}{l}\text { Artefato } \\
\text { mágico }\end{array}$ & item & Canalizar magia +3 para encantarias \\
\hline & Zarabatana & 3 & Munição $(3 / 10)$, recarga, índio +2 de dano \\
\hline
\end{tabular}

Fonte: História e imaginação no Maranhão republicano, 2019, manuscrito ainda não publicado.

Seguindo a mesma lógica dos outros elementos do jogo, pensamos em magias específicas para cada clã e que de alguma forma se relacionassem com o conceito elaborado para cada grupo. Como a magia Artimanhas de Cazumba das Encantarias: por meio dela, o encantado pode invocar o espírito de Cazumba, personagem folclórico das manifestações de bumba meu boi do Maranhão. Quando se evoca essa magia, o jogador escolhe o inimigo mais próximo e o espírito rodeia o alvo. $\mathrm{O}$ inimigo deve rolar um dado de seis lados - d6. Se o resultado for entre 4 e 6 , ele fica intimidado pelo Cazumba, concedendo vantagem de combate até o começo do próximo turno do encantado.

Uma das magias relacionadas aos Quilombolas é a Bênção dos orixás. Por meio dela, o quilombola canaliza os espíritos dos orixás. Ele deve rolar um dado de vinte faces - $1 \mathrm{~d} 20$ - e escolher um dos efeitos: se tirar de 1 a 5 pontos ele consegue a benção de Xangô e com isso o personagem ganha força, fica mais robusto, aumentando sua defesa em 2; se tirar de 6 a 10 pontos, ele consegue um Pai preto e, então, conjura um raio de luz que dá dano nos oponentes, rolando um dado de 12 faces - $1 \mathrm{~d} 12$ - para isso. Como efeito o alvo deve realizar um teste. Se falhar, ele fica cego até o próximo turno do quilombola. 
Estes são apenas alguns exemplos das magias que podem ser utilizadas pelos jogadores.

Todas as características que definem um personagem devem ser incluídas na ficha do personagem. A ficha do personagem funciona como um diário para o jogador. Nela estão contidos todos os atributos sobre o personagem que se pretende interpretar: nome, clã, idade, sexo, alinhamento, entre outras informações. A fase de construção desses dados é uma parte importante para o uso do RPG para fins didáticos, pois neste momento de construção o aluno precisará ler o manual e só assim poderá escolher o seu clã preferido. Almeja-se que nesta fase os alunos possam se interessar ainda mais pela história do estado, pois ele se sentirá instigado em saber mais sobre o seu clã escolhido, o que naturalmente já funciona como um estímulo à pesquisa. Nesse momento, há também um grande estímulo à produção escrita, pois existe um espaço em que o discente deve preencher, a coluna Antecedentes, e nela ele deve escrever a história de seu personagem, sua origem, seus hábitos e costumes.

Cabe destacar ainda que, entre os alunos do projeto, o próprio RPG e suas mecânicas foram testadas e comparadas a outros sistemas na questão de qualidade e facilidade de entendimento. Quanto à parte do combate, foi simplificado para priorizarmos a narrativa. Assim, os alunos podem se envolver mais na história. Pensando nisso, e com a parte sistemática do jogo definida, começamos a definir a fase final do projeto, a construção da narrativa principal. A campanha proposta pelo jogo é inspirada na mais conhecida lenda do estado, tendo como peça importante a Grande Cobra que cerca a cidade de São Luís, capital do estado. Ao longo da trama proposta pelo manual, os jogadores precisarão interagir com integrantes de outros clãs, além de entrar em contato com uma série de criaturas fantásticas que compõem o imaginário popular e folclórico do estado, a exemplo do Rei Sebastião, encantado dos Lençóis maranhenses, local onde reina soberano. Reza a lenda que ele aparece em forma de touro e se um dia for desencantado, o Maranhão vai por água abaixo. Há uma cantiga famosa naquele local, que diz: "rei, rei, rei, rei Sebastião / Se desencantar lençóis, vai abaixo o Maranhão” (FERRETTI, 2000, p. 78).

A ideia de um manual que mesclasse toda a leveza da brincadeira, do lúdico trazido pelo RPG, com os acontecimentos debatidos pela historiografia do Maranhão foi o planejado para gerar interesse dos alunos sobre a história da região. O livro-manual apresenta informações sobre os referidos grupos 
pesquisados, apresentando-os de forma lúdica, interativa e divertida, não como um ponto de chegada, mas como um ponto de partida para novas pesquisas e descobertas. Assim, lendo o manual no intuito de montar a ficha do personagem, criar uma história para os personagens, e mesmo na interação com outros jogadores, no meio de uma campanha ou fora dela, os alunos aprendem um pouco sobre a sua própria história, sobre a cultura e a sociedade maranhenses.

História e imaginação no Maranhão republicano é um jogo de interpretação de papeis: o jogador deve contar a história e atuar assumindo o papel do personagem escolhido. Apesar dos acontecimentos históricos criarem a base de construção social dos clãs, é a imaginação o elemento principal da interpretação dos aventureiros, pois é ela, junto com a criatividade do jogador, que irão conduzir a diversão. Assim foi construído todo um Maranhão encantado, em que Dom Sebastião mistura-se com indígenas em lutas para salvar o estado de forças obscuras desconhecidas. Para isso, foi importante planejar que todos os monstros do jogo fossem retirados das lendas e folclore regionais. Na aventura criada, os jogadores enfrentam situações que colocam lado a lado diferentes grupos, criando relações entre esses diferentes clãs que colaboram para um melhor entendimento das dificuldades e história de cada um deles. Mais que isso, ter este encontro de diferentes ajuda o leitor a perceber em outros níveis a composição social de nossa terra, da grande pluralidade e diversidade cultural que compõe o estado do Maranhão.

\section{REFERENCIAS}

BITTENCOURT, Circe Maria Fernandes. O Saber Histórico na Sala de Aula. São Paulo: Contexto, 2012.

BOTELHO, Joan. Conhecendo e debatendo a história do Maranhão. $3^{\mathrm{a}}$ ed. São Luís: Gráfica e Editora Impacto, 2019.

CARDOSO, Eli Teresa. Motivação Escolar e o Lúdico: o jogo de RPG como estratégia pedagógica para o ensino de história. Dissertação (Mestrado). Faculdade de Educação, UNICAMP, Campinas, 2008

FAIRCHILD, Thomas Massao. Leitura de impressos de RPG no Brasil. Tese (Doutorado). Faculdade de Educação, USP, São Paulo, 2007.

FERREIRA, Clarice. O papel da empatia histórica na compreensão do outro. In: Educação Histórica: investigação em Portugal e no Brasil: actas das quintas jornadas 
internacionais de educação histórica. Braga: Centro de Investigação em Educação, 2009.

FERRETTI, Mundicarmo Maria Rocha. Maranhão Encantado: encantaria maranhense e outras histórias. São Luís: UEMA, 2000.

FIGUEIREDO, Luciene Dias. Empates nos babaçuais: do espaço doméstico ao espaço público - lutas de quebradeiras de coco babaçu no Maranhão. Dissertação (Mestrado). Centro Agropecuário: Embrapa Amazônia Oriental, UFPA, Belém, 2005.

GOMES, Márcio Henrique Baima. Ensino de história do Maranhão nas escolas públicas do estado: Limites e possibilidades. In: XXVIII Simpósio Nacional de História, 2015, Florianópolis-SC. Anais eletrônicos.

MACHADO, Meri Emeli Alves. Ensino de história e imaginação histórica: estudantes e representações do passado em uma escola de novo Hamburgo. Dissertação (Mestrado em Ensino de História). Universidade Federal do Rio Grande do Sul, Porto Alegre, 2018.

MARCATTO, A. Saindo do quadro: uma metodologia lúdica e participativa baseada no role playing game. 2. ed. São Paulo: A. Marcatto, 1996.

MELO, Francivaldo. História do Maranhão. São Luís: Gráfica \& Editora Alpha, 2009.

PEREIRA, Juliano da Silva. Uma máquina do tempo movida à imaginação: RPG e empatia histórica no ensino de história. Dissertação (Mestrado em História Social). Centro de Letras e Ciências Humanas, Universidade Estadual de Londrina, Londrina, 2014.

JANN, Priscila Nowaski; LEITE, Maria de Fátima. Jogo do DNA: um instrumento pedagógico para o ensino de ciências e biologia. Ciênc. $\operatorname{cog} n$., Rio de Janeiro, v. 15, n. 1, p. 282-293, abr. 2010.

RODRIGUES, Sonia. Roleplaying game e a pedagogia da imaginação no Brasil. Rio de Janeiro: Bertrand Brasil, 2004.

SCHMIT, Wagner Luiz. RPG e Educação: alguns apontamentos teóricos. Dissertação (Mestrado em Educação). Universidade Estadual de Londrina, Londrina, 2008.

SILVA, Josiane Cristina Cardoso da. Comunidades quilombolas, etnopobreza e assistência social: ressignificação do ser pobre em Ariquipá-MA. Dissertação (Mestrado), Programa de Pós-graduação em políticas públicas, Universidade Federal do Maranhão, São Luís, 2014.

SILVA, Jeanne. O jogo de RPG e o ensino de História: criação de um RPG sobre a Revolução Inglesa. Cadernos de História da UFU. Uberlândia: UFU, v. 11, Dez/2002 - Dez/2003, p. 53-66.

WHITE, Hayden. Meta-história: a imaginação histórica no século XIX. São Paulo: EDUSP, 1992. 


\section{NOTAS}

${ }^{1}$ Ana Joaquina Jansen Pereira, popularmente conhecida como Ana Jansen, foi ficou conhecida pois casou-se com o coronel Isidoro Rodrigues Pereira, em fins do século XVIII e início do XIX um dos homens mais ricos da província do Maranhão. De uma jovem "desonrada" que engravidou antes do casamento, motivo pelo qual teria sido expulsa de casa pelos pais, ela passou, a partir do casamento com o coronel, a ser uma mulher respeitada pela sociedade local. Apelidada de rainha do Maranhão após assumir os negócios da produção de algodão e açúcar na região, depois da morte de seu companheiro e ocupar um importante espaço de influência política. Tornou-se lenda pela fama de autoritária e impiedosa com seus funcionários e escravos, o que é constado por alguns historiadores, que apenas a enquadram aos padrões de comportamento da época. Mas a fama lhe é dada até os dias atuais no estado, com direito a crenças em casarão mal-assombrado e carruagem fantasmagórica errante pelas ruas de São Luís.

${ }^{2}$ Existem dois tipos de quilombos: os históricos, que remontam ao tempo da escravidão (1532 a 1888), que é comumente caracterizado por serem áreas ocupadas por escravos fugidos; e os quilombos contemporâneos. Sobre o conceito de quilombo, ver SILVA, 2014.

${ }^{3}$ No período do governo Vargas, iniciado em 1930, os oligarcas do Maranhão tiveram de seguir as diretrizes do governo federal. $\mathrm{O}$ estado contou com a sucessão de sete interventores diferentes, todos nomeados pelo presidente. Vitorino Freire veio de Pernambuco para o Maranhão para articular localmente um partido de apoio a Vargas. Esse período ficou conhecido como vitorianismo no estado.

${ }^{4}$ Cuxá é uma espécie de molho feito à base da folha de vinagreira, e é típico da culinária maranhense.

${ }^{5}$ Todas as ilustrações foram feitas pela aluna Vitória Cavalcante do curso de Técnico em Edificações do IFMA, campus Santa Inês, que também compôs parte do grupo Acerto Crítico, desenvolvedor do manual.

Artigo submetido 27 de maio de 2020. Aprovado em 24 de agosto de 2020. 